\title{
Non-financial reporting of corporations - a Czech case study
}

\author{
JAROSLAV SEDLÁČEK \\ Department of Finance, Faculty of Economics and Administration \\ Masaryk University \\ Lipová 41a, 60200 Brno \\ CZECH REPUBLIC \\ https://is.muni.cz/auth/person/1112?lang=en
}

\begin{abstract}
Although reporting on the responsibility and beneficial effect of a corporation is becoming standard practice, it is traditionally considered as part of the annual financial performance report in the Czech region. A change to the new form and content was to be ensured by an amendment to the legislation with effect from 1 January 2017. The perception of new approaches has not been investigated or published to date so the aim of the research was to ascertain how the new quality of reporting is applied in Czech corporations. Data for empirical research was excerpted from reports published by large public interest entities in 2018 . To verify the generally perceived assumption of a positive correlation between the size of corporations and the quality of their reports, or more precisely between the quality of reports and the satisfaction of users' needs, the methods of quantitative and qualitative financial analysis were applied. The analyzes have yielded comparable results to global developments in the publication of non-financial information in terms of form and content. Lower representation has been reported in the fight against corruption and environmental protection. The model for measuring the quality of non-financial reports based on a point score confirmed a higher medium to high degree of quality.
\end{abstract}

Key-Words: non-financial information, corporate social responsibility, corporate annual report, environmental, social and governance reporting, global reporting

Received: November 5, 2019. Revised: May 9, 2020. Accepted: May 20, 2020. Published: May 27, 2020.

\section{Introduction}

The term non-financial reporting began to emerge in the early 1990s to distinguish it from the financial statements provided by corporations to users of accounting information. It is quickly taking its place beside financial reporting and is essential for assessing the value of corporations and their existence in the long-term horizon.

New approaches to measuring and reporting value have been triggered by the demands of prominent corporate leaders. A number of scientific studies, articles and scholarly publications published at the end of the last and the beginning of this session are devoted to clarifying the nature of non-financial information, its structure, quality and form. Professor Robert G. Eccles [1] demanded a shift from purely financial data to an emphasis on quality, market share, customer satisfaction, and other non-financial measures. The motivation of non-financial reporting is the Stakeholders theory, which states that corporations cannot operate without regard for their stakeholders. The origin of the theory is attributed to Professor R. Edward Freeman [2], who described organizational management and business ethics in detail, dealing with morality and values in corporate governance. He identified the most important interest groups that have a direct or indirect influence on a corporation (both positive and negative) or which the corporation itself directly or indirectly influences by its operations and activities.

There is a need for the long-term sustainability of development, which is defined in different ways, but most commonly referred to as the Brundtland Report (WCED): "Sustainable development is a development that meets today's needs without compromising the ability of future generations to meet their own needs" [3]. Sustainable development goals (SDGs) are a roadmap for a better and more sustainable future for all and were issued by the UN General Assembly in 2015 with a deadline of 2030 and are part of UN Resolution 70/1, Agenda 2030. There is a change in the view of securing social development, which is currently focused mainly on financial reporting in the form of data on the characteristics and organization of business corporations. The origin of this reporting is put into the period of the industrial revolution and the emergence of a new type of business that allowed the concentration of capital of a large number of investors. The traditional source of information was 
accounting, which provided information on the financial situation and performance of business corporations. Regulation was taken care of by the government by issuing laws, decrees, standards, or other legislative standards. The United Kingdom publishes the Companies Act (1844), which requires companies to present their balance sheets to shareholders and enter them in the register. The main principles and fundamentals of financial reporting have been entrusted to private, professional, non-profit organizations. In 1934 it was the Financial Accounting Standards Board (FASB), which issued the US GAAP and on the international level, the International Accounting Standards Board (IASB), which started issuing IAS in 1971, later called IFRS. The scope, content and form of reporting have evolved in response to the growing needs of users, especially owners, potential investors, employees, the state, the region, business partners, creditors and others.

Modern information systems that integrate financial and non-financial development level indicators are suitable for assessing individual states and their groupings, regions and corporations are referred to as Environmental, Social and Governance Reporting (ESG) or Global Reporting Initiative (GRI). Originally general reporting frameworks created by expert groups within national and multinational organizations (UNESCO, OECD, IOSCO, WBCSD,

\section{Problem Formulation}

The importance of non-financial (soft) data in the evaluation of business corporations was confirmed by a multifactor analysis carried out in Czech industrial corporations by the Faculty of Economics and Administration of Masaryk University, which resulted in designing models for evaluating not only their financial success but also their beneficial effect [6]. A successful business corporation must also be beneficial for its stakeholders [7]. At the same time, economic growth in the form of an increase in the capital of business corporation owners is accompanied by environmental and social impacts. Information users want to know how corporations are doing in the area of Corporate Social Responsibility (CSR) that is defined as a commitment by corporations to act in accordance with the values and goals of our society. CSR logically also applies to other corporate activities that may affect customers and the outside world.) and what the economic, environmental and social impacts of their daily activities are. Social responsibility and the long-term sustainability of development are the essence of non-financial
EU and others) as non-binding are currently being made mandatory. In the Czech Republic, this obligation was introduced in 2004 by Act No 437/2003, which amends Act No. 563/1991 Coll., on Accounting, following a European Commission (EC) directive, for companies that are issuers of securities registered on a regulated securities market in the Member States of the European Union.

As of 1 January 2017, the amendment to Accounting Act No. 462/2016 requires large business corporations, which are also public interest entities, to disclose and verify non-financial information if, at the balance sheet date, it exceeds the criterion of an average of 500 employees during the accounting period. Non-financial information must now include, in particular, information on:

a) social,

b) respect for human rights; and

c) the fight against corruption and bribery.

The aim is to find out which requirements laid down for non-financial reporting of analyzed corporations are neglected.

As reported by Kašparová and Škapa [4] or later Malíková et al. [5] many companies began to report environmental and social information, but the content and form varied greatly. The aim is to find out which requirements laid down for non-financial reporting of analyzed corporations are neglected.

information. Economist Milton Friedman described corporate social responsibility as notable for its analytical freedom and lack of rigor [8]. According to Marrewijk [9], the need for non-financial information arises from the balance of the principle of self-determination of the community principle: entities are part of a larger whole and should therefore adapt to changes in their environment and respond to remedies by their stakeholders.

Ioannou and Serafeim [10] reported that the lack of commitment of companies with the community and the lack of transparency of their impact on society has created the idea of mandatory corporate social responsibility (CSR). The transition from voluntary corporate social responsibility to compulsory has been particularly notable for large companies. Structured, formalized and codified approaches are progressively applied from the informal publication of information. The research of Wang and Choi [11] confirms that meeting stakeholder needs has a positive impact on company performance. Companies develop and implement stakeholder engagement procedures, implement methods for measuring and long-term reporting of non-financial information. 
Empirical studies published by Gonzalez-Ramos et all. [12] suggest that proactive companies are able, to develop better relationships with stakeholders and are more involved in CSR than those characterized as followers or innovators. Here are two main reasons that justify these results: (i) CSR practices assist companies with retaining highly qualified employees, helping to maintain their leadership position; and (ii) technology leaders tend to be more involved in CSR as a way of collecting valuable knowledge that can be useful in exploring new opportunities through innovation, allowing the business to respond more flexibly to market changes and the needs of new stakeholders as well as to change their preferences. In addition, CSR initiatives will contribute to the development of high-value intangible assets, such as corporate reputation, which in turn will boost the company's financial performance [13].

As it emerged from a survey carried out by an audit and consulting company EY [14], non-financial information cannot be considered an ancillary item in the annual report beyond the financial statements, but becomes an essential part of investor decisionmaking processes. There was a dramatic increase in the number of respondents from $35 \%$ to almost $60 \%$ between 2013 and 2014, who consider CSR or sustainability reports to be important when making investment decisions. In the context of numerous violations of corporate ethics or related scandals, the main challenge is to provide transparent and valueoriented reporting that includes non-financial information and will be designed to stimulate stakeholder confidence.

Similarly, Deloitte [15] found that businesses are no longer assessed solely on the basis of traditional metrics such as financial performance or the quality of their products or services. Today, businesses are increasingly being judged by their relationships with workers, customers and communities, as well as their impact on society as a whole transforming from business to social enterprises. Social capital is in many ways a newfound value alongside the value of financial and physical capital. Successful businesses today need to perceive external trends, perspectives and requirements by maintaining positive relationships not only with customers and employees, but also with local communities, regulators, and many other stakeholders. This shift reflects the growing importance of social capital in shaping the purpose of a business, leading stakeholders and influencing its ultimate success or failure. According to the survey, $18 \%$ of companies consider the CSR program a key strategic priority, $26 \%$ rank the program in their priorities and $56 \%$ do not intend to implement it.

A detailed look at the global trends in CR reporting is provided by survey by KPMG [16], which was performed at the TOP 100 companies by revenue (N100) on the global sample of 4,900 companies and 250 of the world's largest Fortune 500 companies (G250). Research has confirmed the growing growth of corporate responsibility reporting and its inclusion in annual reports is a standard practice. As shown in Figure 1, more than three-quarters of the world's 250 largest companies now report at least some non-financial information in their annual financial reports.

Many countries have adopted the concept of integrated financial and non-financial reporting and have issued regulations and stock exchange guidelines, leading to a $73 \%$ increase in CR reporting by large companies. France (93\% of the 100 largest companies), Great Britain (90\%), Norway (86\%) and Denmark (82\%) were the best performing non-financial reporting countries in Europe.

Although the Act requiring non-financial reporting came into force on 1 January 2017, there is still no information on the status of non-financial reporting in the Czech region. 
Figure 1: The rate of corporate responsibility reporting among the N100 and G250

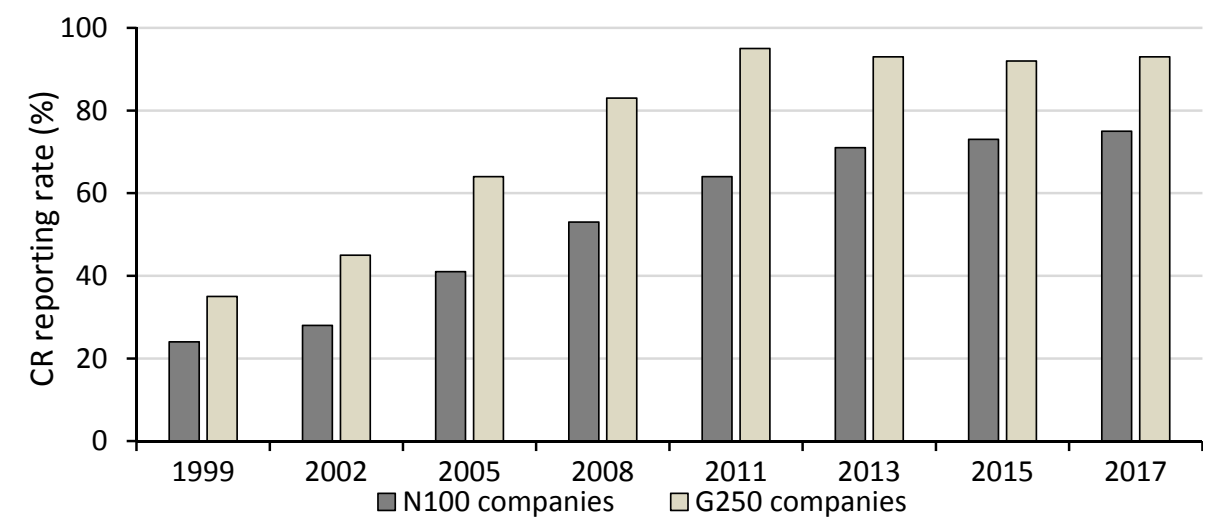

Source: Authors' calculation based on data from KPMG [16].

In our research, which is the subject of this paper, we have therefore focused on the quality of the referenced information with regard to meeting the needs of users in the economic, environmental, social and governmental administration areas. We are looking for an answer to the research question of how the new quality of reporting is perceived by Czech manufacturing industry corporations. The basis for the empirical research is data excerpted from the financial statements and annual reports issued in 2018. It is a logical continuation of the research in which we analyzed the information behavior of corporations traded on the Czech capital market in the period 2013 - 2017. The research sample contained 264 reports that were analyzed and tested for a quantitative reporting approach. The aim is to find out whether the deviations in the reporting of the analyzed corporations are significant for their users.

Czech legislation perceives the asymmetry of information between corporate management and users of external information in the form of financial statements as a problem that non-financial information, which is a difficult to quantify source of significant value that can fill the gap between book value and market capitalization, thus significantly contributing to a company's reputation, can contribute to. Since 2004, the audited corporations have been obliged to prepare an annual report containing information on facts after the balance sheet date, the anticipated development of the corporation, activities in the areas of research and development, environmental protection, labor law relations, etc. Since 2017, the obligation of nonfinancial reporting for large entities has been extended to the areas of social affairs, respect for human rights and the fight against corruption.

The introduction of compulsory non-financial reporting is the result of a logical trend, as according to a survey of audit firms and ESF MU research, most large companies have been publishing nonfinancial information for some time (see Fig. 1 and 2). This was due to the fact that, in addition to economic information, social, environmental and administrative information reinforces, in the eyes of stakeholders, the trust, reputation and usefulness of the corporation in the long run and ultimately its success.

Figure 2: The share of SMEs and large corporations reporting non-financial information (in \%)

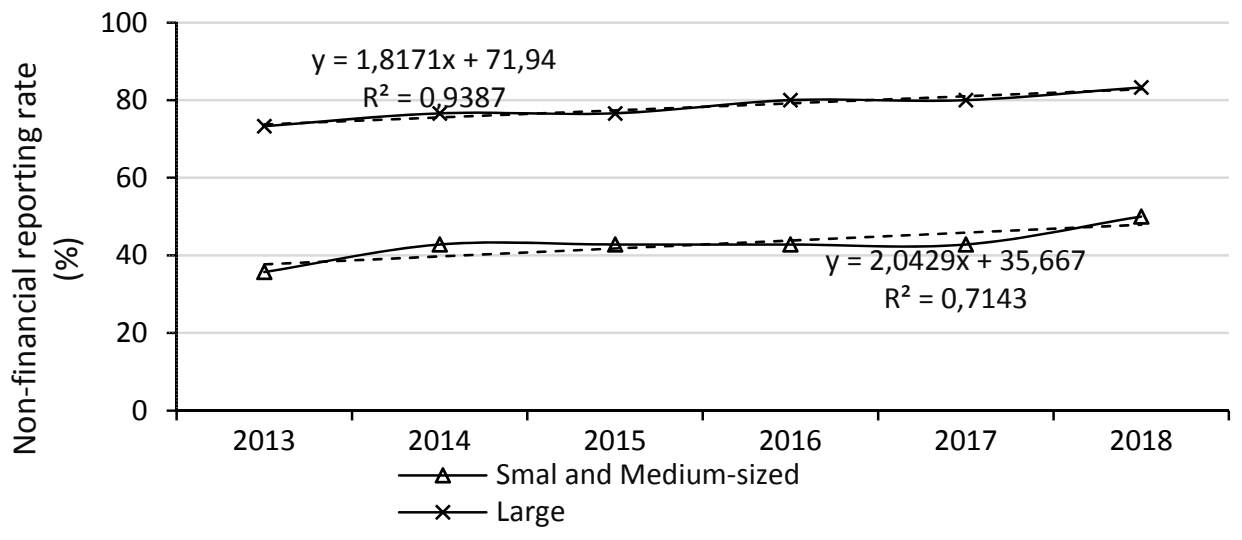




\title{
Source: Authors' calculation based on corporate data in a research sample
}

The methodology of the research is based on empirical data, which are excerpted from the reports of business corporations including ecological, social and administrative information apart from economic information. The research is focused on comparative analysis, which enables assessing the form and content of published reports in terms of the amendment to the Accounting Act 2016. The research sample included 44 large corporations, which are required by law to disclose non-financial information. The structure of corporations is shown in Fig. 3.

Figure 3: Structure of corporations

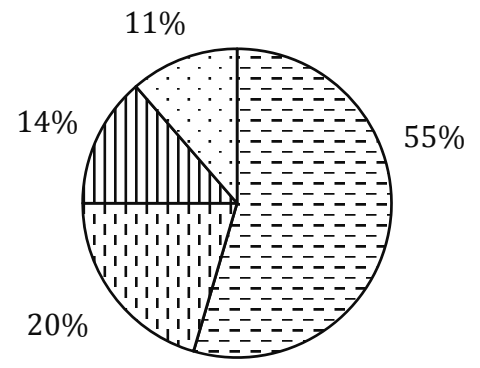

\author{
曰 Business companies \\ 口Banking institutions \\ DInsurance companies \\ $\square$ Health insurance
}

Source: Authors' calculation based on corporate data in a research sample

More than half of the corporations in the sample are Business Companies, whose management expects the positive impact of non-financial reports on performance, growth in production demand and higher sales.

The excerpted data is then subjected to comparative financial analysis, which is divided methodically into two interconnected parts. A method of quantitative analysis that assesses and evaluates mutually comparable and measurable data, in particular the form of reports, their scope, proportions in terms of the level of non-financial reports and their adequacy with the requirements under the amended Accounting Act. The qualitative method is based on the evaluation of the interrelationship between economic and noneconomic phenomena, the internal and external environment of corporations, future orientation and the set goals. The quality of non-financial reports is assessed mostly verbally in the context of the requirements stipulated by the amendment to the Act. As the independent quality assessment in the audit reports is aimed at assessing the compliance of non-financial information with the regulations in the Other information paragraph, the own rating-based methodology was chosen (see Table 1).

Table 1: Qualitative characteristics of scoring information

\begin{tabular}{llc}
\hline Level of information & \multicolumn{1}{c}{ Description } & Points \\
\hline Low & $\begin{array}{l}\text { General description of the activities carried out in the given } \\
\text { period }\end{array}$ & 1 \\
\hline Lower middle & $\begin{array}{l}\text { Comprehensive description needed to understand the state of } \\
\text { activities, their development and the impact on internal and } \\
\text { external environments. }\end{array}$ & 2 \\
\hline Medium & $\begin{array}{l}\text { Description of risks and their management, including measures } \\
\text { to eliminate them. }\end{array}$ & 3 \\
\hline Higher medium & $\begin{array}{l}\text { Strategic dimension of information in the context of the long- } \\
\text { term sustainability of development activities. }\end{array}$ & 4 \\
\hline High & Usefulness and relevance in the context of user needs. & 5 \\
\hline Excellent & $\begin{array}{l}\text { Completeness and transparency in relation to internationally } \\
\text { recognized standards, norms and rules. }\end{array}$ & 6 \\
\hline
\end{tabular}




\section{Problem Solution}

\subsection{Quantitative (technical) financial analysis}

The analysis confirmed that large corporations operating in the Czech territory are striving for more than profit and, in line with current world trends, publish information on the impact of their activities on society and its development. All monitored corporations published non-financial information in the year under review. Non-financial reports may be published in accordance with the amendment to the Act in the form of an annual report or a separate report, which may be prepared according to the methodology governing the publication of CSR reports. The analyzed sample included annual individual and consolidated reports and separate reports in the form of CSR, ESG and GRI. As demonstrated by the analysis results shown in Fig. 4 , more than half of the corporations used the classic annual report. The content of these reports was mainly the information required by accounting legislation in force before the amendment. Separate reports provided a more detailed look at responsible corporate behavior and their impact on the environment. More than half of the separate reports were compiled according to the internationally recognized GRI standard.

Figure 4: Forms of non-financial reporting
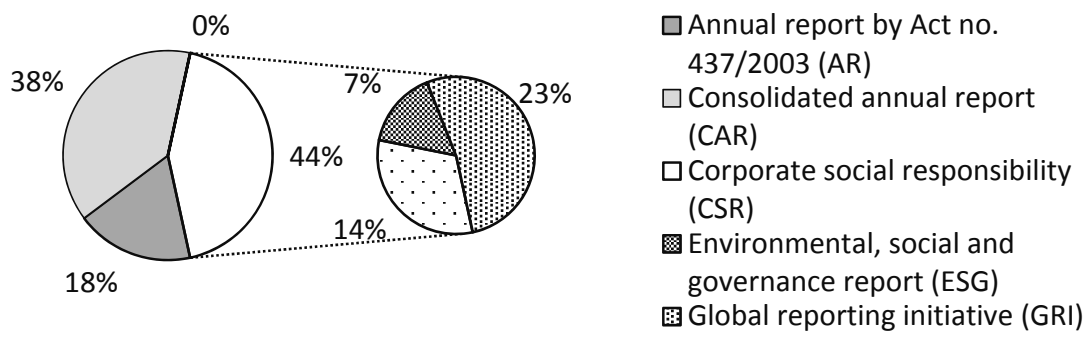

Source: Authors' calculation based on corporate data in a research sample

The scope of the reports is determined by the importance of corporations in terms of their position on the labor market, impacts on the environment and economic impact. The median number of pages published was 204.5 between a minimum of 38 and a maximum of 492 pages. The frequency of the report range measured at a constant interval is evident from Fig. 5.

Figure 5: Report range frequency

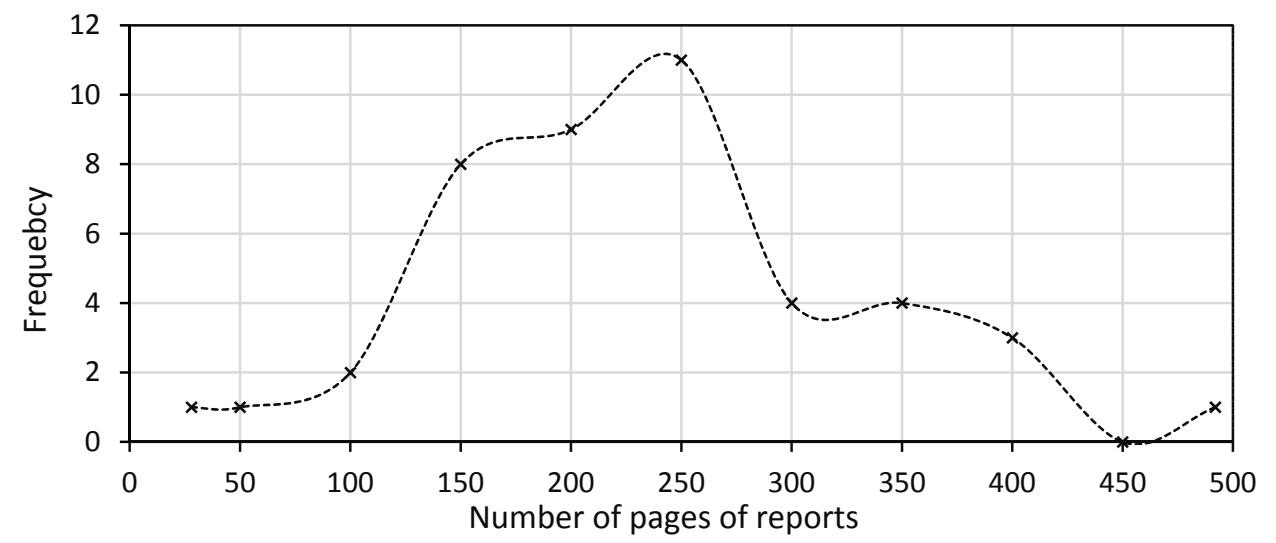

Source: Authors' calculation based on corporate data in a research sample

In order to assess and evaluate how the corporations surveyed comply with the principles of the new European legislation on non-financial reporting, we have focused on the four basic areas required by the amendment to the Accounting Act. The assumption that not all corporations approach reporting in all the 
listed categories responsibly has been confirmed. As shown in Fig. 6, all the corporations analyzed have expanded their reports to include information regarding respect for human rights. Ninety-seven percent of the corporations analyzed reported CSR activities in their reports. Eighty-eight percent of reports describe protecting the environment from pollution arising due to self-produced waste. The fight against corruption and bribes was the last ranking of the imaginary ranking, where a large proportion of corporations (39\%) avoided the issue.

Figure 6: Share of disclosure non-financial information in areas required by law

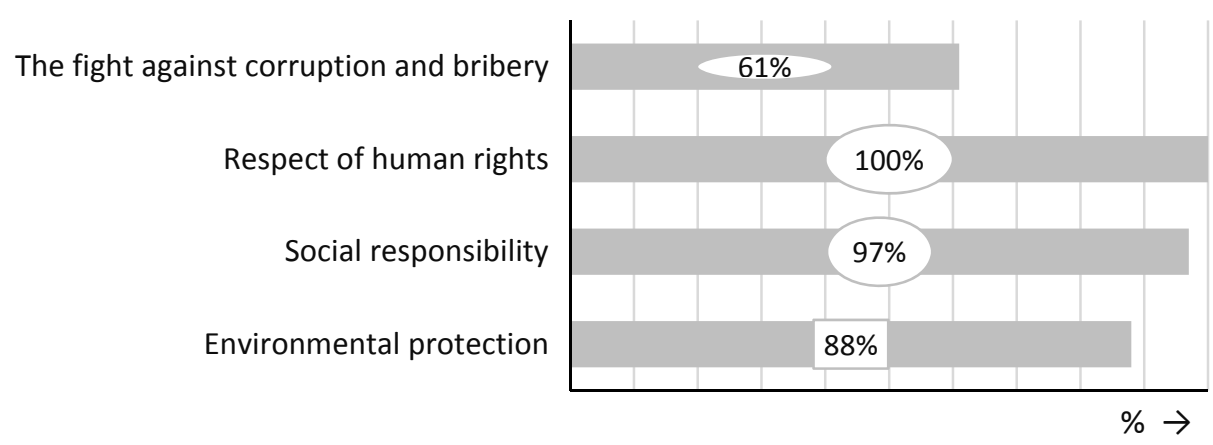

Source: Authors' calculation based on corporate data in a research sample

\subsection{Qualitative (fundamental) financial analysis}

The aim of the qualitative analysis is to assess and evaluate whether the published non-financial information enables an objective and balanced understanding of the development of a business corporation or group of corporations, its performance, position and impact of its operations. This is the qualitative level of information provided on:

a) the business model of the business corporation, b) the measures and their results in the fields of environmental protection, social and employment fields, respect for human rights and the fight against corruption and bribery; c) the principal risks associated with the activity of the business corporation and, where appropriate, its business relationships, products or services, which could have adverse effects in these areas, and the way in which those risks are managed,

d) non-financial key performance indicators related to the relevant business activity.

Report quality is evaluated according to the model specified in Tab. 1 in six levels. The frequencies at which the individual report quality levels occurred are measured. As shown in Fig. 7, the highest frequency was found in corporations whose reports showed a high of quality level. The average value is 4.45 points, which corresponds to the quality between the higher medium and high level of reports.

Figure 7: Frequency of reports broken down by quality

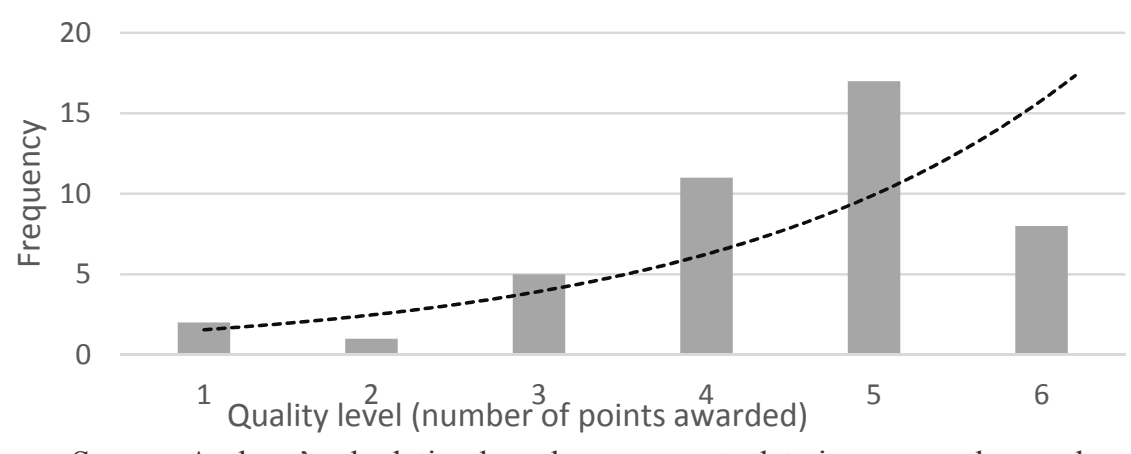

Source: Authors' calculation based on corporate data in a research sample

The high quality of the reports is supported not only by ethical and legal motives but also by the credibility of the users. Credibility is influenced by the supranational capital of large corporations and by the verification of the accuracy of the disclosures by internal bodies (board of directors for risk 
management, supervisory board, internal audit committee) and verification by third parties. All the reports reviewed were audited by positive audit firms in the Other Information section of the audit report. The structure of audit firms is shown in Fig. 8.

Figure 8: The structure of audit firms

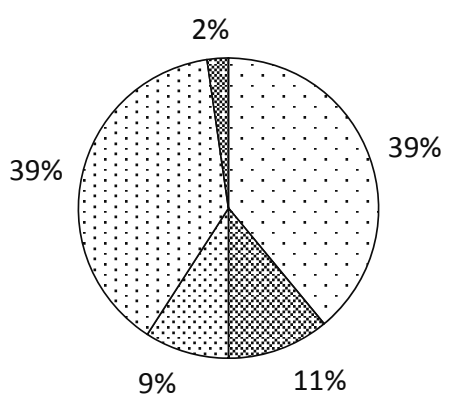

\author{
$\square$ PriceWaterhouseCoopers \\ 圆 Ernst \& Young \\ Deloitte \\ $\square$ KPMG International Cooperative \\ 四 Fineco
}

Source: Authors' calculation based on corporate data in a research sample

\section{Conclusion}

In this paper, we examined how corporations in the Czech Republic perceived new reporting requirements not only on economic activity, but especially on the impact of their activities on society as a whole. The research focused on assessing and evaluating the quantitative characteristics of reporting and the qualitative level of reports. Source data of empirical research were obtained from a sample of joint-stock corporations that met the size criterion and were also public interest entities. Reports in the form of financial statements and annual or separate reports were excerpted from a total of 44 joint-stock corporations that were actively engaged in their core business in 2018 . The aim of quantitative empirical analysis was to classify reports in terms of the form, structure, scope and methodology used. The results of the analysis confirmed that most corporations used the classic annual report that contained the information required by accounting legislation in force before the amendment to the Accounting Act. A more detailed look at responsible corporate behavior and its impact on the environment was contained in separate reports prepared at the CSR, ESG or GRI level.

As shown in Fig. 6, not all corporations published non-financial information in all four basic areas required by the amendment to the legislation. The lowest number of publications was found in the fight against corruption and bribery and environmental protection.

The quality of non-financial reports is assessed mostly verbally in the context of the requirements set out in the amendment to the Act, including a description of the business model. The quality level was evaluated by the point method and the frequency of publication was measured. The results of the analysis confirmed that the quality of nonfinancial reports is at a higher medium to high level. Even more than $18 \%$ of reports received an excellent rating. Corporations have recognized the importance of responsible behavior, transparency and ethics for owners, investors, employees and the community.

The benefit of this study is new scientific knowledge in the process of non-financial reporting in terms of quantity, quality and shortcomings of reports, which is the basis and inspiration for other scientific projects aimed at greater usefulness and benefits of non-financial reports.

\section{Acknowledgement}

The author is thankful to the Internal Grant Agency of Masaryk University, Faculty of Economics and Administration No. MUNI/A/1110/2018 "Nonfinancial information and its relevance for measuring performance".

\section{References:}

[1] Eccles, R. G., Krzus, M. P. One Report: Integrated Reporting for a Sustainable Strategy. John Wiley \& Sons: New Jersey, 2010.

[2] Freeman, R.E. Strategic Management: A Stakeholder Approach. Cambridge University Press: USA, New York, 2010.

[3] World Commission on Environment and Development. Our Common Future. 1983. Available at: https://sustainabledevelopment.un.org/content/d ocuments/5987our-common-future.pdf. 
[4] Kašparová, K., Škapa, R. Insight into Corporate Social Responsibility practices of Czech companies. Journal of Global Strategic Management, Vol. 2, No. 3, 2008, pp. 47-57.

[5] Malíková, O., Brabec, Z., Rozkovec, J. Financial reporting of intangible assets evidence on information and communication companies in the Czech Republic. Journal of International Studies, Vol. 11, No. 2, 2018, pp. 327-340.

[6] Blažek, L. Research of business success factors. In: Ekonomika firiem: Proceedings of the International Conference. Faculty of Business Administration, Košice, Slovak Republic, 2001, pp. 48-53, part. 1.

[7] Sedláček, J., Valouch, P. Valuation of the target company in the process of the mergers and acquisitions using discounted cash flow method. WSEAS Transactions on Business and Economics, Vol. 11, 2014, pp. 747-756.

[8] Waddock, S.A., Bodwell, CH., Graves, S.B. Responsibility: The new business imperative. Academy of management perspectives, Vol. 16, No. 2, 2002, pp. 132-148.

[9] Marrewijk, M. Concepts and Definitions of CSR and Corporate Sustainability: Between Agency and Communion. Journal of Business Ethics, Vol. 44, No. 2, 2003, pp 95-105.

[10] Ionnau, I., Serafeim, G. The Consequences of Mandatory Corporate Sustainability Reporting. HBS Working Paper 2017, Series 11-100.

Available at:

https://papers.ssrn.com/sol3/papers.cfm?abstrac tid $=1799589$.

[11] WANG. H. and CHOI, J. A. New Look at the Corporate Social-Financial Performance Relationship: The Moderating Roles of Temporal and Interdomain Consistency in Corporate Social Performance. Journal of Management, Vol. 39, No. 2, 2010, pp. 416441.

[12] Gonzales-Ramos, M.I., Donate, M.J., Guadanillas, F. The Effect of Technological Posture and Corporate Social Responsibility on Financial Performance Through Corporate Reputation. International Journal of Innovation, Vol. 6, No. 2, 2018, pp. 164-179.

[13] Sedláček, J., Lemeshko, O. The reporting of goodwill in national and international context: Evidence from the Czech Republic. WSEAS Transactions on Business and Economics, Vol. 13, 2016, s. 260-268.

[14] EY's Report. The Road to Reliable NonFinancial Reporting, 2016. Available at: https://www.slideshare.net/turloughguerin(eys- report-the-road-to-reliable-nonfinancial-

reporting-2016.

[15] Deloitte. Global Human Capital Trends, 2018. Available at:

https://www2.deloitte.com/au/en/pages/humancapital/articles/human-capital-trends.html.

[16] KPMG's Report, 2017. Available at: https://home.kpmg/xx/en/home/campaigns/201 7/10/survey-of-corporate-responsibilityreporting-2017.html 